\title{
La familia de crianza: una mirada comparada entre Estados Unidos y Colombia*
}

\author{
I Karol Ximena Martínez-Muñoz** \\ - Camilo Andrés Rodríguez-Yong***
}

RESUMEN. La aparición de nuevas realidades sociales ha llevado a reconocer formas de familia diferentes de las basadas en vínculos jurídicos o de consanguinidad. De esta manera, se ha abierto paso a la protección de una estructura familiar sustentada en una situación fáctica acompañada de lazos de afecto, solidaridad y protección. En el caso colombiano, la jurisprudencia ha desarrollado el concepto de "familia de crianza". Por su parte, en los Estados Unidos las cortes han acudido a las doctrinas de in loco parentis y adopción por equidad.

Palabras Clave: familia de crianza, in loco parentis, adopción por equidad.

* Fecha de recepción: 28 de junio de 2019. Fecha de aceptación: 30 de marzo de 2020.

Para citar el artículo: Martínez-MuÑoz, K. X. y RodríGuez-Yong, C. A., "La familia de crianza: una mirada comparada entre Estados Unidos y Colombia", Revista de Derecho Privado, n. 39, juliodiciembre 2020, 85-107, DoI: https://doi.org/10.18601/01234366.n39.05.

Este artículo se realizó en desarrollo del trabajo de investigación del grupo de Derecho Privado de la Facultad de Jurisprudencia de la Universidad del Rosario.

** Universidad del Rosario, Facultad de Jurisprudencia, Bogotá, Colombia; profesora de carrera. Magíster, Università degli Studi di Messina, Messina, Italia.Contacto: karol.martinez@urosario.edu.co. Orcid: 0000-0001-5242-5973.

*** Universidad del Rosario, Facultad de Jurisprudencia, Bogotá, Colombia; catedrático. LLM y SJD, Indiana University Maurer School of Law, Bloomington, Estados Unidos de América. Contacto: camilo.rodriguez@urosario.edu.co.Orcid: 0000-0003-3897-5404. 


\section{Foster Family: A Comparative Look between the United States and Colombia}

Abstract. The appearance of new social realities has led to the conception and protection of family forms different from those based on legal ties or consanguinity. In this way, mechanisms to protect family structures originated from a factual situation accompanied by ties of affection, solidarity and protection have been developed. In the Colombian case, jurisprudence has developed the concept of "foster family". On the other hand, in the American union the courts have resorted to the doctrines of in loco parentis and equitable adoption.

KEYwORDs: foster family, in loco parentis, equitable adoption.

SUMARIO: Introducción. I. Familia de crianza, adopción por equidad e in loco parentis. II. Rasgos distintivos. Conclusiones y comentarios finales. Referencias.

\section{Introducción}

La aparición de nuevas realidades sociales ha llevado a concebir y proteger formas de familia diferentes de las basadas en vínculos jurídicos o de consanguinidad ${ }^{1}$. De esta manera, se ha abierto paso a la protección de una estructura familiar sustentada en una situación fáctica acompañada de lazos de afecto, solidaridad y protección.

La aceptación de esta estructura familiar ha tenido lugar en algunos países, como Colombia y los Estados Unidos. Así, en el caso colombiano, la jurisprudencia ha desarrollado el concepto de "familia de crianza". Por su parte, en la Unión americana las cortes han acudido a las doctrinas de in loco parentis y adopción por equidad (equitable adoption) (también conocida con los nombres de specific performance of an agreement to adopt, virtual adoption o adoption by estoppel $)^{2}$.

1 En esta dirección, véase Robinson, J., "Untangling the 'loose threads': equitable adoption, equitable legitimation, and inheritance in extralegal family arrangements", Emory Law Journal, Emory University School of Law, vol. 48, n. 3 , 1999, 943-945. Véase también: Higdon, M., "When informal adoption meets intestate succession: the cultural myopia of the equitable adoption doctrine", Wake Forest Law Review, Wake Forest University School of Law, vol. 43, n. ${ }^{\circ}$ 1, 2008, 223-281.

2 "Sin embargo, otras jurisdicciones han empleado la jurisdicción de equidad general para evitar dificultades al determinar si existió una adopción válida con miras a permitir participar al menor en los frutos de una sucesión intestada. Este uso de la equidad es efectuado bajo varios nombres: ejecución de un acuerdo para adoptar, adopción virtual, estoppel o adopción por equidad. Sin importar el nombre dado, estas diversas teorías descansan directamente sobre la máxima de la equidad de que "la equidad considera como hecho lo que debería haberse realizado". Alaska Supreme Court. Calista Corp. v. Mann, 564 P.2d 53 (1977) (traducción libre de los autores). Véase también: Johnson, I., "A suggested solution to the problem of intestate succession in nontraditional family arrangements: taking the 'adoption' (and the inequity) out of the doctrine of 'equitable adoption"', Saint Louis University Law Journal, Saint Louis University School of Law, vol. 54, n. ํ. 1, 2009, 274. 
Dentro de este marco, el artículo realiza una investigación jurídico-comparativa con el propósito de exponer las visiones colombiana y estadounidense respecto del tratamiento que la jurisprudencia les otorga a estas formas de familia. Con este objetivo, el texto se divide en tres partes principales. En el primer acápite se exponen algunas generalidades de las doctrinas mencionadas. Posteriormente, desde una perspectiva comparada, se identifican sus rasgos distintivos más importantes. Finalmente, en una tercera sección, se proponen algunas sugerencias frente a una posible regulación de la doctrina de la familia de crianza, en el contexto colombiano.

\section{Familia de crianza, adopción por equidad e in loco parentis}

La familia de crianza desarrollada por la jurisprudencia colombiana puede definirse como aquella forma excepcional de familia que conlleva una relación de hecho, fundamentada en la convivencia, el afecto, la protección, el auxilio y el respeto ${ }^{3}$, que dada su importancia para la estabilidad y el desarrollo de quienes hacen parte de ella, especialmente los menores de edad, es sujeta de protección ${ }^{4}$.

En las familias de crianza existe un estrecho vínculo entre un núcleo de personas que asumen de forma voluntaria y permanente las obligaciones de crianza y protección. Este vínculo es atestiguado por la sociedad, está sustentado en el aprecio, el acompañamiento, el soporte económico y el apoyo emocional ${ }^{5}$, y permite considerar a este grupo como una familia tradicional ${ }^{6}$. Es importante destacar que aunque la doctrina de la familia de crianza busca principalmente proteger a los hijos, la jurisprudencia ha extendido también su ámbito de protección a los padres ${ }^{7}$.

Por consiguiente, a través de la familia de crianza se crea, de facto, una unidad de vida o familiar ${ }^{8}$. De allí que la Corte Constitucional colombiana haya señalado:

Como corolario de lo anterior, es viable afirmar que el pluralismo y la evolución de las relaciones humanas en Colombia tiene[n] como consecuencia la formación de distintos tipos de familias, diferentes a aquellas que se consideraban tradicionales, como lo era la familia biológica. Por ello, "es necesario que el derecho se ajuste a las realidades jurídicas, reconociendo y brindando protección a aquellas relaciones familiares en las que las personas no están unidas única y exclusivamente por vínculos jurídicos

3 Corte Constitucional. Sentencia T-525 del 27 de septiembre de 2016; Corte Suprema de Justicia. Sala de Casación Civil y Agraria. Sentencia del 23 de octubre de 2015, rad. 250012213000201500361-02.

4 Corte Constitucional, sentencia T-292 de 2004.

5 Corte Constitucional, sentencia T-233 de 2015. Consejo de Estado, Sección Tercera, sentencia del 14 de septiembre de 2016, rad. n. ${ }^{\circ}$ 81001-23-31-000-2009-00035-01.

6 Corte Constitucional, sentencia T-281 de 2018.

7 Corte Constitucional, sentencia T-233 de 2015.

8 Corte Constitucional, sentencia T-525 de 2016. 
o naturales, sino por situaciones de facto, las cuales surgen en virtud de los lazos de afecto, solidaridad, respeto, protección y asistencia"9.

De esta manera, la familia de crianza constituye una clara expresión del denominado "derecho viviente", pues a partir del reconocimiento de una realidad social ${ }^{10}$ se imponen obligaciones y derechos a determinados sujetos. La familia de crianza es, por tanto, un ejemplo de cómo la jurisprudencia responde a los desarrollos de la sociedad para llenar un vacío en la ley ${ }^{11}$.

En el caso de Estados Unidos, la jurisprudencia ha desarrollado las doctrinas de adopción por equidad y de in loco parentis. La adopción por equidad, doctrina aceptada por varios estados de la Unión americana ${ }^{12}$, tiene lugar cuando a una persona que ha sido tratada como un hijo se le ha prometido su adopción o esta se ha considerado, pero esta nunca se llevó a cabo ${ }^{13}$.

El reconocimiento de la doctrina de adopción por equidad se explica teóricamente desde dos perspectivas: el contrato y la equidad ${ }^{14}$. En virtud de la primera, se entiende que el padre no biológico ha prometido llevar a cabo la adopción legal del menor. Por lo tanto, se pretende hacer realidad dicha promesa ${ }^{15}$. Por su parte, bajo la perspectiva

9 Corte Constitucional, sentencia T-177 de 2017.

10 "Debe partirse de la base que la legislación no cubre todas las situaciones posibles y que incluso presenta importantes contradicciones. La ciencia del derecho no es feliz a la hora de explicar situaciones simples, que caen fuera de las grandes estructuras jurídicas como son la teoría de la capacidad, o de la posesión. Explicaciones divergentes han sido dadas para encuadrar los contratos de compraventa de cosas muebles por menores de edad, verbigracia el caso del adolescente que sin tener capacidad para actos lícitos compra útiles escolares, lo mismo sucede con su capacidad para poseer lo que ha adquirido. Estos hechos caen, sin duda, dentro de lo que se denomina "el derecho vivo". [...] La vida está llena de situaciones que son resueltas de forma diversa de lo prescripto por las leyes. Estas ocasiones son reguladas por normas ínsitas en la conciencia social. No obstante su dispersión y volatilidad, estos principios reúnen los caracteres que les hacen merecer el nombre de Derecho, en tanto regulan relaciones ideales entre sujetos, y gozan de coercibilidad. Se trata de sanciones informales, muy relevantes dentro de la vida de un grupo de pertenencia, e incluso más eficaces que las mismas sanciones estatales, puesto que pueden significar la pérdida inmediata de la posición social relativa (el status), importante para el sujeto y su entorno". Messio, P., "La función social del derecho. El derecho vivo", Revista de la Asociación de Magistrados y Funcionarios de la Justicia de la Nación [en línea], IJ Editores, vol. 39/40, enero/junio, 2006. Disponible en [http://ijeditores.com/articulos. php?idarticulo=48986\&print=2] [consultado el 20 de noviembre de 2018]. En el mismo sentido: LoRCA Martín de Villodres, M., "La experiencia jurídica actual desde la clásica doctrina filosófica de la naturaleza de las cosas", Persona y derecho, Universidad de Navarrra, vol. 68, n. ${ }^{\circ}$ 1, 2013, 56, 75.

11 Corte Constitucional, sentencia T-281 de 2018.

12 DRAKE, R., "Status or contract? a comparative analysis of inheritance rights under equitable adoption and domestic partnership doctrines", Georgia Law Review, vol. 39, n. ${ }^{\circ}$ 2, 2005, 681.

13 "En su esencia, la doctrina de la adopción por equidad permite a una persona que fue aceptada y tratada como un hijo natural o adoptado, y a quien la adopción fue prometida o contemplada pero nunca realizada, participar en la sucesión de las propiedades de los padres adoptivos." In Re Estate of Ford, 82 P.3d 747, 2004 (traducción libre de los autores).

14 Petri, C., "What's in a Name? Not Much for Equitable Adoption in Missouri", Missouri Law Review, vol. 63, n. ${ }^{\circ}$ 1, 1998, 195. Véase asimismo Johnson, op. cit., 275-293.

15 En los Estados Unidos el contrato se define como un intercambio de promesas. En esta dirección, véase: Farnsworth, E., Contracts, $4^{\text {th }}$ ed., Aspen Publishers, New York, 2004. 3. 
de equidad, lo que se busca es proteger a los menores ante la negligencia u omisión de los padres adoptivos de no hacer lo que en equidad les correspondía realizar ${ }^{16}$.

La adopción por equidad tiene importantes diferencias con la adopción tradicional. Así, mientras la adopción no puede ocurrir de forma póstuma, la adopción por equidad requiere que el padre o madre haya fallecido. Igualmente, mientras la adopción tiene que ver con el estatus o relación entre padre e hijo, la adopción por equidad se refiere a un derecho de propiedad relacionado con los bienes del fallecido ${ }^{17}$. Por otra parte, mientras la adopción da lugar a un vínculo legal entre padres e hijos, la adopción por equidad no lo crea. Lo anterior, habida cuenta de que la adopción es un asunto netamente legal, de tal suerte que el poder para crear una relación de filiación entre hijo y padre solo puede surgir por la decisión del legislador ${ }^{18}$. Finalmente, la adopción tiene carácter real (in rem), razón por la cual es vinculante frente a todas las personas, y el adoptado es titular de todos los derechos derivados de una adopción legal. Por el contrario, la adopción por equidad es de naturaleza personal, de lo que se sigue que solamente vincula a las partes involucradas.

La teoría de la doctrina de adopción por equidad ha sido criticada principalmente por considerarse que desincentiva el cumplimiento de las disposiciones que regulan la adopción, afectándose, por tanto, las medidas de protección perseguidas con dichas normas. Así, se ha indicado:

Aunque la adopción por equidad parece ser una doctrina favorable para los miles de padres que desean hijos y para los niños que buscan hogares estables, existen algunas preocupaciones de que eludir los procedimientos legales de adopción generará más daño que bien. Existen normas de adopción para garantizar que los niños se encuentren en un entorno adecuado. Si las personas perciben que pueden lograr el equivalente a la adopción legal sin tener que seguir las dispendiosas y costosas disposiciones legales, tambalearán las normas y salvaguardas diseñadas por estas ${ }^{19}$.

17 "Las diferencias entre una adopción y una ‘adopción por equidad' son muchas, como se discute más detalladamente a continuación. Por ejemplo, no hay ninguna disposición en el capítulo 453 sobre la adopción póstuma; mientras que la adopción por equidad es de naturaleza póstuma. Goldberg, 615 S.W.2d en 61-63. Más importante aún, una adopción se refiere al estado de padre e hijo, mientras que una 'adopción por equidad' se trata de un derecho de propiedad relacionado con el fallecido". Missouri Court of Appeals, Coon v. American Compressed Steel, 133 S.W.3d 75, 2004 (traducción libre de los autores).

18 "La adopción es un asunto puramente de ley. Véase Menees v. Cowgill, 359 Mo. 697, 223 S.W.2d 412, 415 (Mo. 1949), cert. denegado, 338 U.S.949, 94 L. Ed. 585, 70 S. Ct. 488 (1950). No había derecho de adopción bajo el derecho común de Inglaterra. 2 Am.Jur.2d, Adopción, $\beta 7$ (1994). La regla universal en todos los estados es que el poder de crear la relación de padre e hijo entre personas no así relacionadas existe solo por virtud de la ley. Id. No hay autorización legal para la adopción diferente al Capítulo 453. Engel v. Kenner, 926 S.W.2d 472 (Mo. App. 1996)”. Idem (traducción libre de los autores).

19 Traducción libre de los autores. Survey. "Deference Defiantly Denied: The Fourth Circuit Rejects NLRB Position on $\S 8(f)$ Pre-hire Agreements in Industrial TurnAround Corp. v. NLRB", North Carolina Law Review, vol. 76, n. ${ }^{\circ}$ 6, 1998, 2480. 
Igualmente, se considera que la doctrina abre la puerta a múltiples interrogantes, tales como: ¿puede el menor adoptado heredar de los parientes de sangre del padre adoptante?, ¿puede el menor heredar tanto del padre biológico, como del adoptante? ${ }^{20}$ También surgen preguntas frente a la posibilidad de aplicar la doctrina en el caso de parejas homosexuales, en aquellos estados de la Unión americana que no permiten la adopción legal por parte de estas ${ }^{21}$.

En lo que respecta a la doctrina de in loco parentis, esta tiene lugar cuando una persona se coloca por su propia voluntad en la posición de padre o madre de otra, de tal manera que asume las obligaciones que corresponden a dicha calidad ${ }^{22}$. Lo anterior, sin que se haya adelantado legalmente un proceso de adopción ${ }^{23}$.

\section{Rasgos distintivos}

\section{A. Las razones que fundamentan el reconocimiento de estas formas de familia}

Las doctrinas estudiadas encuentran sustento en múltiples y variadas razones. Así, en el caso colombiano, el reconocimiento de las familias de crianza halla justificación en la necesidad de proteger a aquellas personas, especialmente menores, que sin tener vínculos de consanguinidad o legales con un determinado núcleo familiar, fueron tratadas como parte de este.

La protección de dichos sujetos se fundamenta en los artículos $1 .^{\circ}$ y 95 de la Constitución Política de Colombia. De allí que a través de la doctrina de las familias de crianza se hagan realidad importantes mandatos de la Constitución, al desarrollar, por una parte, el deber de solidaridad social que tienen todos los colombianos, y, por otra, el deber de protección integral de la familia que tienen a su cargo tanto

20 Petri, op. cit., 220.

21 WARNER, L., "Local government law symposium: student work: bending the bow of equity: three ways Florida can improve its equitable adoption policy", en Stetson Law Review, vol. 38, n. . 3 , $2009,581$.

22 Fougeron, K., "Equitable Considerations for Families with Same-Sex Parents: Russell v. Bridgens, 264 Neb. 217, 647 N.W.2d 56 (2002), and the Use of the Doctrine of In Loco Parentis by Nebraska Courts", Nebraska Law Review, vol. 83, n. ${ }^{\circ} 3,2005,926$.

23 'La frase 'in loco parentis' se refiere a una persona que se coloca en la situación de un padre legítimo al asumir las obligaciones relacionadas con la relación parental sin pasar por la formalidad de una adopción legal. El estado de in loco parentis encarna dos ideas; primero, la asunción de un estatus parental, y segundo, el cumplimiento de los deberes parentales. Los derechos y responsabilidades derivadas de una relación in loco parentis son, como las palabras implican, exactamente las mismas que entre padre e hijo. Sin embargo, el tercero en este tipo de relación no puede colocarse en un estatus in loco parentis desafiando los deseos de los padres y la relación padre/hijo". Tribunal Supremo de Pensilvania, Tb v. Lrm, 786 A.2d 913 (2001). Véase también: Levine, B., "Divorce and the modern family: providing in loco parentis stepparents standing to sue for custody of their stepchildren in a dissolution proceeding", Hofstra Law Review. Hofstra University Maurice A. Deane School of Law, vol. 25, n. ${ }^{\circ}$ 1, 1996, 324-325 (traducción libre de los autores). 
el Estado como la sociedad colombiana. Por consiguiente, la familia de crianza es un claro ejemplo del fenómeno de la constitucionalización del derecho de familia ${ }^{24}$.

Desde el punto de vista legal, la protección de los integrantes de la familia de crianza, basada en el deber de solidaridad, tiene fundamento legal en el artículo 67 del Código de la Infancia y la Adolescencia, disposición que establece que

El Estado reconocerá el cumplimiento del deber de solidaridad que ejerce la familia diferente a la de origen, que asume la protección de manera permanente de un niño, niña o adolescente y le ofrece condiciones adecuadas para el desarrollo armónico e integral de sus derechos. En tal caso no se modifica el parentesco.

El reconocimiento de las familias de crianza encuentra también justificación en la necesidad de garantizar la prevalencia de lo sustancial sobre lo formal. Así, bajo esta forma de familia, prevalece la voluntad inequívoca de padres e hijos de conformar una familia basada en el buen trato, el afecto y la asistencia mutua ${ }^{25}$. De esta suerte, la familia de crianza no responde a una perspectiva formal, sino a una sustancial, que el derecho no puede desconocer ${ }^{26}$, pues de hacerlo se vulnerarían la unidad familiar y el desarrollo integral y armónico de los menores de edad ${ }^{27}$.

Además, la familia de crianza materializa el derecho de una persona a tener una familia ${ }^{28}$ y permite la realización del mejor interés del niño. Así, el derecho de los niños a tener una familia y no ser separados de ella se manifiesta, por regla general, en el seno de su familia biológica. Esta presunción encuentra fundamento legal en múltiples normas e instrumentos nacionales (Código de la Infancia y de la Adolescencia) e internacionales (la Convención sobre los Derechos del Niño, artículos 7-1 y 9-1, la Declaración de las Naciones Unidas sobre los Derechos del Niño (principio 6), la Declaración de las Naciones Unidas sobre los Principios Sociales y Jurídicos Relativos a la Protección y el Bienestar de los Niños, con Particular Referencia a la Adopción y la Colocación en Hogares de Guarda, en los Planos Nacional e Internacional, y el Convenio de La Haya relativo a la Protección del Niño y a la Cooperación en Materia de Adopción Internacional de 1993).

Ahora bien: la presunción en favor de la familia biológica puede ser desvirtuada cuando su mantenimiento o reconocimiento no permite garantizar el bienestar del menor, o conlleva riesgos o peligros para este ${ }^{29}$. De allí que la presunción deje de operar en el caso de menores que han sido criados dentro del marco de una familia

24 Frente a la constitucionalización del derecho de familia véase: EsBorraz, D. F. "El concepto constitucional de familia en América Latina. Tendencias y proyecciones", Revista de Derecho Privado, n. ${ }^{\circ} 29$, julio-diciembre de 2015, 15-55.

25 Corte Constitucional, sentencia T-495 de 1997.

26 Corte Constitucional, sentencia T-111 de 2015.

27 Corte Constitucional, sentencia T-606 de 2013.

28 Corte Constitucional, sentencia T-217 de 1994.

29 Corte Constitucional, sentencia T-292 de 2004. 
de crianza, en donde se entiende que el interés superior del menor se satisface de mejor manera al no ser interrumpido su proceso de desarrollo como consecuencia de su ubicación familiar ${ }^{30}$.

En esta dirección, se ha indicado:

Cuando el derecho del menor a la familia ha circunscrito su ámbito de protección al grupo familiar de crianza, y ha operado el cese correlativo de la presunción a favor de la familia biológica, el Estado debe abstenerse de intervenir en las relaciones familiares de hecho, salvo que medien circunstancias que, como las señaladas, hagan prever que el menor no se desarrollará adecuadamente en su seno. Si la familia de crianza no presenta ninguna de las circunstancias que se indican, las autoridades de Bienestar Familiar deberán abstenerse, en virtud del interés superior del menor, de perturbar las relaciones intrafamiliares dentro de dicha familia de crianza, mucho más si como consecuencia de sus actuaciones, el menor resulta separado de tal núcleo de parientes ${ }^{31}$.

En el caso de la experiencia de los Estados Unidos, las doctrinas de adopción por equidad y de in loco parentis buscan proteger al menor y realizar importantes valores y principios, tales como la justicia, la igualdad y la buena $\mathrm{fe}^{32}$. Por ejemplo, se ha señalado que mediante la adopción por equidad se pretende corregir "la injusticia que resultaría de aplicar inflexiblemente las leyes sobre sucesión intestada" ${ }^{33}$. En efecto, en los Estados Unidos la sucesión intestada es un asunto regulado por la ley. Es ella la que establece el orden y la manera como deben distribuirse los bienes de una persona al fallecer. De esta suerte, la adopción por equidad permite que una persona que no aparece dentro de las llamadas por la ley a heredar, por no tener un vínculo de sangre o legal con el causante, pueda, en todo caso, hacerlo ${ }^{34}$.

En términos similares al caso colombiano, en las doctrinas de adopción por equidad e in loco parentis predomina la realidad sobre lo formal. En consecuencia, las doctrinas miran más allá de un estatus legal, con el propósito de adentrarse en la relación real que el individuo comparte con las personas que lo han integrado a su núcleo familiar ${ }^{35}$. De esta suerte, se otorgan efectos jurídicos a situaciones de hecho, en aras

30 Idem.

31 Corte Constitucional, sentencia T-497 de 2005.

32 "En conclusión, se debe decretar la adopción por equidad donde la justicia, la equidad y la buena fe lo requieran." Supreme Court of North Carolina, Lankford v. Wright, 347 N.C. 115, 1997. Véase también: Strachman, D., "Equitable Adoctrine doctrine", Rhode Island Bar Journal, vol. 64, 2016.

33 Supreme Court of Illinois, James R.D. v. Maria Z. (In re Scarlett Z.-D.), 28 N.E.3d 776, 2015.

34 Respecto a la sucesión intestada y las doctrinas de adopción por equidad e in loco parentis véase: JoHNSON, op. cit.

35 "Ciertamente, la doctrina de la adopción por equidad es un ejemplo del enfoque funcional en el sentido de que mira más allá del estatus legal y observa la relación real que el individuo compartió con el difunto". Supreme Court of Illinois, James R. D. v. Maria Z. (In re Scarlett Z.-D.), 28 N.E.3d 776, 2015 (traducción libre de los autores). 
de materializar importantes derechos (por ejemplo, en materia sucesoral, de custodia y alimentos, entre otros).

Finalmente, el aseguramiento del mejor interés del niño también ha servido de fundamento para las señaladas doctrinas. Así, en el caso de la denominada in loco parentis, los derechos de los padres naturales son atemperados ante la necesidad fundamental de proteger dicho interés. De allí que la presunción en favor de la autonomía y privacidad de la familia natural desaparezca cuando el niño ha establecido fuertes lazos sicológicos con una persona que, aunque no es su pariente biológico, ha vivido con el niño y le ha dado cuidado y afecto, asumiendo a los ojos del menor la calidad de padre o madre. Por lo tanto, en virtud del mejor interés del niño debe darse la oportunidad a dicha persona de mantener esa relación, aunque el padre natural se oponga ${ }^{36}$.

\section{B. Las consecuencias jurídicas derivadas de las doctrinas de familia de crianza, adopción por equidad e in loco parentis}

En el caso colombiano, acogiendo la jurisprudencia de tribunales internacionales como la Corte Europea de Derechos Humanos, se ha señalado que cuando un menor de edad ha sido separado de su familia biológica para ser cuidado por una familia diferente durante un periodo de tiempo lo suficientemente amplio para desarrollar vínculos afectivos entre el menor y los integrantes de la segunda familia, y la modificación de dichos vínculos afectaría el interés superior de aquel, la protección derivada del derecho del menor a tener una familia y a no ser separado de ella se transfiere a la familia de crianza. En otras palabras, la protección de la familia biológica cede su espacio para proteger a la familia de crianza del menor ${ }^{37}$.

En virtud del deber de protección a las familias de crianza contra toda forma de discriminación, el Estado debe ofrecer las mismas garantías y prerrogativas reconocidas a las familias constituidas a partir de lazos naturales. De allí que, por ejemplo, la jurisprudencia nacional haya señalado que quien hace parte de una familia de crianza tiene el derecho a acceder a las mismas indemnizaciones y prestaciones que

36 "El principio de la doctrina de in loco parentis que reconoce la necesidad de proteger a la familia de las intrusiones de terceros y los derechos del padre natural debe ser limitada por la necesidad primordial de proteger el interés superior del niño. Por lo tanto, si bien se presume que el interés superior del niño se beneficia al mantener la privacidad y la autonomía de la familia, esa presunción debe ceder cuando el niño ha establecido fuertes lazos psicológicos con una persona que, aunque no es su padre biológico, ha vivido con el niño y brindado atención, cuidado y afecto, asumiendo a los ojos del niño una importancia como la de un padre. Cuando se advierte una relación de este tipo, nuestros tribunales reconocen que el interés superior del niño demanda que se le reconozca legitimidad al tercero para que tenga la oportunidad de litigar la cuestión de si esa relación debe mantenerse incluso sobre la objeción de un padre natural." Tribunal Supremo de Nebraska, Latham v. Schwerdtfeger, 802 N.W.2d 66, 2011 (traducción libre de los autores).

37 Corte Constitucional, sentencia T-292 de 2004. 
le corresponden a los familiares de sangre ${ }^{38}$. Igualmente, ha ordenado el pago de pensiones $^{39}$ e indemnizaciones a los hijos de crianza, y reconocido a estos como beneficiarios de planes de salud o como miembros de clubes de trabajadores ${ }^{40}$.

En consonancia con lo anterior, la familia de crianza impone a sus integrantes la asunción de derechos y deberes que comúnmente tienen los miembros de una familia biológica. Así, tienen el deber de tratarse con respeto y buscar una armonía que beneficie el crecimiento de todo el núcleo familiar ${ }^{41}$. Adicionalmente, los padres deben velar por que sus hijos disfruten de un ambiente propicio para el ejercicio de sus derechos y con las atenciones requeridas para su desarrollo integral ${ }^{42}$.

Asimismo, la jurisprudencia constitucional colombiana consideró, inicialmente, que con la familia de crianza surgía una relación de parentesco ${ }^{43}$. Por lo tanto, dicha relación implicaba, atendiendo el derecho a la igualdad, que existían idénticas consecuencias jurídicas en materia de derechos y obligaciones entre las familias de crianza y las biológicas ${ }^{44}$.

Ahora bien: todo lo anterior parece alterarse con la aparición de la sentencia C-085 de 2019. En esta decisión, la Corte Constitucional da un viraje importante a su postura, al señalar que los hijos de crianza "no son una categoría de sujetos comparable" con los hijos por consanguinidad o adoptivos y que la crianza no es fuente de filiación, al tratarse de un asunto de competencia del legislador ${ }^{45}$.

El cambio de posición de la Corte Constitucional resulta positivo por dos razones principales. En primer lugar, es concordante con lo establecido en el artículo 67 del Código de la Infancia y la Adolescencia, el cual determina que la familia de crianza no genera un vínculo de parentesco.

En segundo lugar, las relaciones de parentesco deben ser efectivamente un asunto de competencia del legislador, en su calidad de máximo órgano democrático, y no de las autoridades judiciales, las cuales carecen de representatividad popular.

38 Corte Constitucional, sentencia T-281 de 2018.

39 Consejo de Estado, Sección Tercera, sentencia del 27 de noviembre de 2017, rad. 25000-23-42-0002017-02526-01(AC).

40 Corte Constitucional, sentencia T-606 de 2013. Véase también: Corte Suprema de Justicia, Sala de Casación Civil, sentencia del 9 de mayo de 2018, rad. 25000-22-13-000-2018-00071-01.

41 Idem.

42 Corte Constitucional, sentencia T-887 de 2009.

43 Corte Constitucional, sentencia T-177 de 2017

44 “Afectación del principio de igualdad, que configura idénticas consecuencias legales para las familias de crianza, como para las biológicas y jurídicas, en cuanto a obligaciones y derechos y, por tanto, el correlativo surgimiento de la protección constitucional": Corte Constitucional, sentencia T-525 de 2016.

45 "El reconocimiento que esta Corporación le ha otorgado a la familia de crianza no ha llegado a definir los efectos jurídicos que tiene sobre la filiación y el parentesco de las personas que hacen parte de ella. En otras palabras, y en la medida que es una tarea que compete exclusivamente al legislador, no ha establecido en términos generales la capacidad para ejercer derechos y contraer obligaciones de los hijos y padres de crianza como sí ocurre en las relaciones parentales que surgen a partir de vínculos de consanguinidad o por adopción": Corte Constitucional, sentencia C-085 de 2019. 
La postura asumida recientemente por el tribunal constitucional colombiano se observa cercana a la doctrina de adopción por equidad, cuyo ámbito de aplicación se limita, por regla general, al campo sucesoral ${ }^{46}$. En virtud de lo anterior, no es dable alegarla en asuntos tales como el parentesco, la custodia y las visitas al menor ${ }^{47}$. Con todo, excepcionalmente ${ }^{48}$ se ha acudido a la adopción por equidad para exigir el pago de alimentos a menores ${ }^{49}$.

Dentro de las razones que se han esgrimido para limitar el ámbito de aplicación de la doctrina se encuentran las siguientes: (1) se trata de asuntos regulados por la ley ${ }^{50}$; (2) si la doctrina aplicara de forma amplia, se abriría la puerta para que "cada hombre que sale o está casado con una mujer que permite a sus hijos llamarlo 'papá' corra el riesgo de pagar alimentos a los menores cuando la relación termine y cada mujer tendría el riesgo de que su ex novio/esposo instaure una petición solicitando la custodia de su hijo" 51 ; y (3) permitir a una persona que no es el padre legal reclamar la custodia sobre un menor atenta contra el derecho fundamental del padre legal a criar a sus hijos ${ }^{52}$.

Por otra parte, la doctrina de adopción por equidad no da lugar a una relación legal de padre e hijo. Tampoco crea o reemplaza a la adopción legal, ni constituye un mecanismo para evitar los procedimientos de adopción ${ }^{53}$.

46 California Supreme Court, In Re Estate of Ford, 82 P.3d 747, 2004.

47 "Estamos de acuerdo con María en que la doctrina de la adopción por equidad, como se reconoce en DeHart, es un concepto legítimo para determinar la herencia y no se aplica a los procedimientos de parentesco, custodia y visitas". Supreme Court of Illinois, James RD v. Maria Z. (en Scarlett Z.-D.), 28 NE3d 776, 2015 (traducción libre de los autores). Véase igualmente Corte de Apelaciones de Illinois, En re Marriage of Mancine, 2014 IL App (1st) 1111382014.

48 "Ningún caso de Nuevo México ha abordado si la doctrina de la adopción por equidad puede aplicarse en los procedimientos de manutención infantil. Varios casos fuera de esta jurisdicción han abordado específicamente ese tema y se han negado a aplicar la doctrina en dichos casos". Tribunal de Apelaciones de Nuevo México, Poncho v. Bowdoin, 2006 nMCA 13 (traducción libre de los autores).

49 "La doctrina de la adopción por equidad aplica la equidad para crear un estatus que confiera ciertos beneficios a un niño, como la manutención de los hijos o una herencia." Poncho v. Bowdoin, 126 P.3d 1221, 2005 (traducción libre de los autores).

50 "En Illinois, la condición de padre para buscar la custodia de un niño está determinada por la ley y no por el derecho consuetudinario.” Idem (traducción libre de los autores).

51 “Como argumenta Miki, si el concepto de 'adopción por equidad' se aplicara en el contexto de los procedimientos de custodia de los hijos, 'cada hombre que sale o está casado con una mujer que permite que el niño lo llame 'Papá' corre el riesgo de que se le exija que pague alimentos al niño cuando la relación termine y cada mujer se arriesga a que su ex novio/esposo solicite la custodia de su hijo." Idem (traducción libre de los autores).

52 “Además, reconocer la adopción por equidad para otorgar legitimación a una parte que busca la custodia en un procedimiento de divorcio, cuando la otra parte es el único padre legítimo, priva a este de su derecho fundamental constitucional de criar a sus hijos." Idem (traducción libre de los autores).

53 "El reconocimiento de la doctrina de adopción por equidad no crea una adopción legal y, por tanto, no perjudica los procedimientos legales de adopción.” Tribunal Supremo de Carolina del Norte, Lankford v. Wright, 347 NC 115, 1997 (traducción libre de los autores). En este sentido se ha señalado: "Dado que la doctrina de adopción por equidad es simplemente un remedio equitativo, no está destinada ni es aplicada para crear una relación legal de padre e hijo, con todas las consecuencias legales de dicha relación, ni pretende crear una adopción legal" (traducción libre de los autores). 
En tratándose de la doctrina de in loco parentis, esta tiene un ámbito de acción mayor a la de adopción por equidad, lo cual ha permitido su aplicación, por ejemplo, en controversias relacionadas con la custodia y visita de menores.

Igualmente, la doctrina de in loco parentis impone a los padres de facto derechos y obligaciones similares a los que tiene un padre legal, cuando ello sea necesario para asegurar el mejor interés del niño ${ }^{54}$.

Con todo, lo anterior debe matizarse en el sentido de que realmente no existe una equiparación absoluta con los derechos y obligaciones del padre biológico o adoptivo. Lo anterior, habida cuenta de que el estatus derivado de la doctrina in loco parentis es temporal, flexible y susceptible de ser suspendido y retomado.

De allí que, en atención a su carácter temporal, no es posible una declaración permanente de la calidad de padre o madre, pues dicha condición puede dejar de existir, dando lugar a que terminen también los derechos y obligaciones correspondientes $^{55}$. Así, una persona considerada padre bajo la doctrina de in loco parentis está facultada para terminar dicha relación, y en consecuencia, poner fin a la obligación de apoyo al menor ${ }^{56}$. El estatus in loco parentis termina, por ejemplo, cuando el padre no biológico establece su hogar en un lugar diferente al del menor e indica su intención de no tratarlo más como parte de su familia ${ }^{57}$.

Por otra parte, bajo la figura de in loco parentis no puede dejarse sin efecto el parentesco derivado de una relación biológica o de adopción ${ }^{58}$. De lo que se sigue, que en caso de que haya una controversia en materia de custodia entre un padre biológico o adoptivo y un tercero, el primero tiene un derecho superior de custodia sobre el menor ${ }^{59}$. Solamente en casos excepcionalísimos la doctrina de in loco parentis puede refutar la presunción en favor del padre natural ${ }^{60}$, lo cual ocurriría, por

54 Nebraska Supreme Court, Whilde v. Whilde, 298 Neb. 473, 2017.

55 "Pero debido a que el estatus in loco parentis es transitorio, hemos señalado específicamente que 'una vez que la persona que está en un estatus in loco parentis ya no cumple con todos los deberes relacionados con la relación parental, ya no está en dicho estatus in loco parentis’ y que la terminación de la relación in loco parentis también termina los derechos y responsabilidades correspondientes otorgadas por el mismo." Idem (traducción libre de los autores).

56 "Además, hemos sostenido que una parte que se encuentra en un estado in loco parentis puede terminar la relación y cualquier deber de manutención correspondiente con el niño." Supreme Court of Arkansas, Foust v. Montez-Torres, 2015 Ark.66, 2015 (traducción libre de los autores).

57 "Nuestro Tribunal Supremo ha sostenido durante mucho tiempo que la relación in loco parentis termina una vez que el padre sustituto ha establecido su hogar en otro lugar, y ha indicado su propósito de no tratarlos como parte de su familia." Tribunal de Apelaciones de Arkansas, McCrillis v. Hicks, 2017 Ark. App. 221, 2017 (traducción libre de los autores).

58 "Para considerarse en un estado in loco parentis, uno debe asumir todas las obligaciones relacionadas con la relación parental. A su vez, una persona in loco parentis generalmente tiene los mismos derechos que un padre legítimo. Sin embargo, el estatus in loco parentis no eclipsa por sí mismo la naturaleza superior de la preferencia parental otorgada a la paternidad biológica o adoptiva." Tribunal Supremo de Nebraska, Jennifer T. v. Lindsay P., 298 Neb. 800, 2018 (traducción libre de los autores).

59 Nebraska Supreme Court, Windham v. Griffin, 295 Neb. 279, 2016.

60 Court of Appeals of Mississippi, Roger Lynn Neely v. Kaleb Matthew Welch, 2014-CA-01022-COA, Miss. Ct. App. 2015, 2015. 
ejemplo, si el tercero ha mantenido económicamente al menor o tratado a este como su hijo, y los padres biológicos no "aparecen realmente en la foto" 61 .

Teniendo en cuenta lo anterior, se ha concluido que el estatus derivado de la doctrina in loco parentis no equivale a la situación de un padre biológico o adoptivo ${ }^{62}$.

\section{Los requisitos para que tengan lugar las doctrinas de familia de crianza, adopción por equidad e in loco parentis}

En lo que respecta a los requisitos que deben satisfacerse para aplicar las doctrinas de familia de crianza, adopción por equidad e in loco parentis, existen importantes similitudes.

Así, la jurisprudencia colombiana exige, en primer lugar, una estrecha relación entre los padres de crianza y el menor. Esto conlleva que exista una convivencia real y efectiva que involucre vínculos de afecto, solidaridad, ayuda y comunicación.

En segundo lugar, debe demostrarse una relación de lazos familiares deteriorada o ausente entre el menor y sus padres biológicos. Esto significa que haya un rompimiento de los vínculos afectivos y económicos entre ellos, como ocurre, por ejemplo, cuando hay desinterés de los padres en fortalecer los vínculos paterno-filiales o de proveer los recursos económicos suficientes para suplir las necesidades básicas de su hijo ${ }^{63}$.

En tercer lugar, una parte de la jurisprudencia ha señalado que el estrecho vínculo que debe existir entre los padres y el hijo de crianza debe ser evidente por un periodo no inferior a cinco años, atendiendo lo establecido por el artículo 398 del Código Civil, el cual consagra dicho término como el tiempo necesario para acreditar la posesión notoria del estado civil de hijo. Así, el Consejo de Estado ha indicado que

[D]ebe probarse que el padre "durante el término mínimo de 5 años, se ha (ya) comportado como tal, proveyendo para la subsistencia, educación, manutención o establecimiento del hijo (trato) presentándolo con este carácter ante la familia y la sociedad,

61 "Y en Pell y J.P.M., el Tribunal encontró ‘que la presunción de los padres naturales había sido superada con base a varios hechos: (1) los esposos estaban en una situación in loco parentis; (2) habían apoyado, cuidado y tratado al niño como si fuera propio; (3) podrían haber sido obligados a pagar la manutención del menor y (4) los padres biológicos no estaban realmente en la foto'. Smith, 97 años, 3d en 47 (I11) (citando a Pell, 881 So. 2d en 186-87; J.P.M., 932 So. 2d en 767-70). En Pell, el padre había renunciado expresamente a sus derechos parentales, y en J.P.M. el padre ni siquiera pudo ser determinado. Véase ID. La Corte Suprema dejó en claro recientemente que la doctrina de in loco parentis y las posiciones de Pell y J.P.M. no ayudan a un padrastro a superar la presunción del padre natural cuando el padre biológico está 'en la foto' y reivindica sus derechos de custodia. Waites, 152 So. 3d en 313-14 (\$18). Debido a que Kaleb está ‘en la foto’, la confianza de Roger en Pell y J. P. M. es equivocada." Idem (traducción libre de los autores).

62 "Aunque en casos anteriores hemos reconocido que el estatus in loco parentis puede dar derecho a una parte a ciertos derechos de custodia y visitas, hemos reconocido que el estatus in loco parentis no es equivalente al estatus de un padre y no le da derecho a la persona a los mismos derechos de un padre legítimo." Tribunal Supremo de Nebraska, Whilde v. Whilde, 298 Neb. 473, 2017 (traducción libre de los autores).

63 Corte Constitucional, sentencia T-705 de 2016. 
que a su vez le reputará y reconocerá el carácter de hijo, y así el hijo le reconozca y se comporte frente al padre" ${ }^{44}$.

Con todo, la Corte Constitucional sigue una regla diferente en relación con el periodo de cinco años, pues considera que la relación afectiva entre padres e hijos debe extenderse por un término razonable o suficiente para establecer la conformación de las relaciones familiares. Por lo tanto, no existe un periodo específico para el efecto, pues este dependerá de cada caso en concreto ${ }^{65}$.

En lo que respecta a los medios de prueba, la relación entre padres e hijos debe demostrarse a partir de expresiones públicas y privadas que realicen las partes, sin que exista una solemnidad particular o un mecanismo específico.

En los Estados Unidos se han identificado igualmente una serie de requisitos que deben ser satisfechos con miras a demostrar una situación de adopción por equidad o in loco parentis. Así, en el caso de la primera, es necesario demostrar la existencia de un acuerdo expreso o implícito entre los padres adoptantes y los padres naturales para adoptar al menor. Para la doctrina, este requisito beneficia la protección de los menores, pues de no existir, las parejas se abstendrían de llevar a sus casas a menores que han sido abandonados por sus padres ${ }^{66}$.

De esta suerte, se requiere que el padre adoptante haya, expresa o inequívocamente ${ }^{67}$, acordado adoptar el niño, o declarado su intención de hacerlo. Lo anterior, puede demostrarse a través de: (1) un contrato escrito para adoptar (lo cual casi nunca se presenta); (2) acciones del padre o madre adoptante que demuestren que han iniciado los trámites necesarios para adoptar al menor (por ejemplo, han consultado un abogado para el efecto, han obtenido el consentimiento escrito del padre biológico, entre otros); y (3) los testimonios del menor, padres biológicos, amigos o familiares que comprueben el acuerdo o la intención de llevar a cabo la adopción ${ }^{68}$.

64 Consejo de Estado, Sección Tercera, sentencia del 5 de diciembre de 2017, rad.: 47001-23-31-0002009-00002-01(41941).

65 “(vi) Existencia de un término razonable de relación afectiva entre padres e hijos, que permita determinar la conformación de relaciones familiares. No se determina a partir de un término preciso, sino que debe evaluarse en cada caso concreto con plena observancia de los hechos que rodean el surgimiento de la familia de crianza y el mantenimiento de una relación estable por un tiempo adecuado para que se entiendan como una comunidad de vida. Esto, porque como lo ha establecido esta Corporación, es necesario que transcurra un lapso que forje los vínculos afectivos, tal y como se describe en el punto 7.5 de esta sentencia”: Corte Constitucional, sentencia T-525 de 2016.

66 MetTa, M. y Markus, S., "Family law: virtual adoption: contractual estoppel of parental rights and responsibilities", The Florida Bar Journal, vol. 71, n. ${ }^{\circ}$ 5, 1997, 90.

67 ReEves, W., "Inheritance by equitable adoption: an overview of theory and proof", Journal of the Missouri Bar, vol. 57, n. 3 , 2001, 130-135.

68 BeAn, E., "Equitable adoption: a look at how to address pitfalls in Texas' complex process", Texas Bar Journal, vol. 81, n. ${ }^{\circ}$ 9, 2018, 682-683. Así mismo, la doctrina ha indicado frente al señalado requisito: "[L]os siguientes factores son indicativos de un acuerdo para adoptar: (1) el niño asumió el apellido del padre adoptivo; (2) el niño fue tratado como el hijo del padre adoptivo; (3) el niño se dirigió al padre adoptivo como 'mami' o 'papi'; (4) el uso por parte del niño del nombre del padre 
Actos de simple amabilidad, o de apoyo económico al menor, o referirse a este como "mi hijo", no son suficientes para demostrar un acuerdo para adoptar, pues se requiere de evidencia que demuestre una verdadera promesa de llevar a cabo el procedimiento de adopción.

Por su parte, en el caso de la doctrina de in loco parentis debe acreditarse que (1) la persona ha asumido intencionalmente los derechos y obligaciones propios de una relación de padre e hijo, lo cual se demuestra mediante actos, conductas y declaraciones; (2) el menor habita en la casa y depende del apoyo económico de la persona; (3) la relación de la persona con el menor es cercana, de apoyo, cuidado y protección; y (4) el padre biológico está ausente ${ }^{69}$.

Como puede observarse, la jurisprudencia colombiana y la estadounidense han establecido un conjunto de importantes requisitos con miras a establecer la existencia de un vínculo consolidado que permita reconocer derechos e imponer obligaciones de índole familiar.

Sin duda alguna, la verificación y aplicación de estos requisitos por parte del juez debe adelantarse forma estricta, teniendo en cuenta las profundas consecuencias que en ámbitos como el sucesoral, de alimentos, y custodia, entre otros, conlleva para los involucrados el reconocimiento de las doctrinas estudiadas.

\section{Conclusiones y comentarios finales}

Comparadas las experiencias colombiana y estadounidense frente al tratamiento dado a una estructura familiar basada en una situación de hecho, es dable señalar lo siguiente:

- Las doctrinas de familia de crianza, adopción por equidad e in loco parentis tienen como propósito proteger a aquellas personas que sin tener un vínculo consanguíneo o legal con un núcleo familiar, son consideradas parte de él. Dicha necesidad de protección constituye el eje central sobre el que se sustentan estas doctrinas.

adoptivo en los registros escolares u otros registros similares; (5) la identificación del niño como dependiente del padre adoptivo en las declaraciones de impuestos; (6) la designación del niño, por parte del padre adoptivo, como su beneficiario en activos no sucesorales; y (7) otras declaraciones o conductas similares de los padres adoptivos a partir de las cuales se puede inferir un acuerdo". Higdon, op. cit., 263-264 (traducción libre de los autores).

69 "Por lo tanto, de acuerdo con las autoridades anteriores, los factores a considerar para determinar si una persona está en un estado de in loco parentis incluyen lo siguiente: (1) la persona está a cargo de derechos y responsabilidades propias de los padres; (2) la persona ha asumido los mismos deberes que un tutor o custodio; (3) la persona ha asumido un rol parental dominante; (4) el apoyo al niño depende de la persona; (5) el niño 'se va a casa' con la persona; (6) la relación de la persona con el niño es cercana, de apoyo y de protección; (7) la persona tiene la intención de actuar como padre, lo cual se demuestra por los actos, la conducta y la declaración de la persona; (8) la persona asume intencionalmente las obligaciones incidentales a la relación parental; y (9) la persona es el cuidador principal del niño mientras el padre biológico está ausente debido, por ejemplo, al empleo." Tribunal de Apelaciones de Ohio, Estado v. Abubakar, 2011-Ohio-6299, 2011 (traducción libre de los autores). 
- Así mismo, las referidas doctrinas reconocen una amplia realidad social que debe ser objeto de tratamiento por parte del legislador, pero que ante la falta de acción de este, debe ser afrontada por el juez, con el propósito de llenar un vacío legal, proteger a las personas involucradas y hacer realidad valores constitucionales y legales como la igualdad, la justicia, la solidaridad y el mejor interés del niño.

- Las doctrinas estudiadas responden a un enfoque psicológico y no legal ${ }^{70}$ del término familia $^{71}$.

- Antes de la sentencia C-085 de 2019 de la Corte Constitucional, era razonable pensar que la doctrina de la familia de crianza ofrecía una mayor protección que sus pares estadounidenses.

Así, en relación a la doctrina de adopción por equidad, el ámbito de la doctrina colombiana no se limitaba al reconocimiento de derechos en el campo sucesoral. Por el contrario, buscaba garantizar que el menor gozara de los mismos derechos que los hijos naturales o adoptados, lo cual permitiría a un hijo de crianza, por ejemplo, exigir el pago de alimentos.

Con la decisión de 2019, parecería incierto el alcance de los derechos de los hijos de crianza frente a materias como el derecho a heredar o recibir alimentos, pues, como lo señaló la Corte, se trata de una categoría que no es comparable con los hijos por consanguinidad o adoptivos. Así mismo, la crianza no es fuente de filiación.

Sin embargo, derechos como los señalados deberían en todo caso ser objeto de reconocimiento, habida cuenta de que la doctrina de la familia de crianza se fundamenta, como se indicó, en los deberes de solidaridad y protección integral de la familia, así como el mejor interés, la protección y el desarrollo integral de los niños.

Por otra parte, aunque la doctrina de familia de crianza está concebida principalmente para proteger a menores de edad, algunas decisiones judiciales han extendido su espectro a la protección de los padres, situación que no parece ocurrir en el caso de la jurisprudencia estadounidense.

En lo que respecta a la doctrina de in loco parentis, aunque esta ha sido aplicada en ámbitos que van más allá de los derechos sucesorales, tampoco conlleva el mismo nivel de protección que la doctrina de familia de crianza, pues, como se indicó, la persona que ha asumido voluntariamente las obligaciones que corresponderían a un padre puede renunciar a ellas cuando así lo desee.

70 Pérez Contreras, M., Derecho de familia y sucesiones, México D. F., Nostra Ediciones, 2010, 23. Véase también: FerRer, F., "Introducción al derecho de familia", en Derecho de familia, tomo I. Rubinzal-Culzoni editores, 1984, 11.

71 Desde una perspectiva psicológica, la familia se entiende como "la unión de personas que comparten un proyecto vital de existencia en común que se supone duradero, en el que se generan fuertes sentimientos de pertenencia a dicho grupo, en el cual existe un compromiso personal entre sus miembros y se establecen intensas relaciones de intimidad, reciprocidad y dependencia". Oliva Gómez, E. y Villa Guardiola, V. "Hacia un concepto interdisciplinario de la familia en la globalización", Justicia Juris, vol. 10, n. ${ }^{\circ}$ 1, 2014, 16; Herrera Guerrero, B.; Weisser Soto, B.; Salazar Salazar, D., "Imágenes y conceptos de familia expresados en las representaciones sociales de mujeres de sectores urbanopopulares de la ciudad de Temuco, Chile”, Límite, Universidad de Tarapacá, vol. 1, n. ${ }^{\circ}$ 11, 2004, 1-34. 
Ahora bien: un reconocimiento amplio a los efectos de las familias de crianza, como el que parecía defender la jurisprudencia constitucional anterior al año 2019, no deja de ser problemático. En primer lugar, igualar a los hijos de crianza con los hijos naturales o adoptivos desincentiva el adelantamiento de procesos de adopción, los cuales están integrados por normas y procedimientos de orden público. De esta suerte, dar un tratamiento igualitario llevaría en la práctica a que las personas, en vez de someterse a los referidos procedimientos y normas, busquen, a partir de la simple fuerza de una realidad, alcanzar el mismo objetivo.

En segundo lugar, se afecta el derecho a la igualdad, pues mientras los integrantes de una familia de crianza tendrían los mismos derechos que aquellos vinculados por motivos civiles o de consanguinidad, en materia de limitaciones o prohibiciones no ocurriría lo mismo.

En efecto, al ser los impedimentos e inhabilidades de interpretación y aplicación restrictiva, pues constituyen una limitación o excepción al ejercicio de un derecho ${ }^{72}$, estos no resultan aplicables a los familiares de "crianza" al no estar incluidos dentro del texto legal. Así, por ejemplo, el artículo 11 de la Ley 1437 de 2011 se refiere únicamente a impedimentos por vínculos civiles o de consanguinidad. Lo mismo ocurre en el caso de las inhabilidades consagradas en la Ley 617 de 2000 para gobernadores, alcaldes y diputados.

En consecuencia, mientras que en el caso de los hijos biológicos o adoptivos se aplican los impedimentos e inhabilidades, en el caso de los integrantes de una familia de crianza no ocurre lo mismo. Lo anterior, a pesar de que en ambos casos es necesario garantizar la transparencia e imparcialidad en la actuación administrativa.

En materia penal, surgirían también importantes dudas frente a la aplicación de las circunstancias de agravación punitiva cuando este inmerso un miembro de la familia de crianza, pues disposiciones como los artículos 166, 170, 179, 188B y 188C del Código Penal (Ley 599 de 2000) se refieren a familiares o parientes vinculados por consanguinidad o civilmente.

Por otra parte, una dificultad que surge de la aplicación jurisprudencial de la doctrina de la familia de crianza radica en los múltiples interrogantes que se derivan de las relaciones del hijo de crianza con su familia biológica o adoptiva: si se considera que un menor es hijo de crianza, ¿desaparecen los derechos y obligaciones de los padres biológicos frente a dicho hijo, o los derechos y obligaciones del hijo frente a estos padres? Si ello es así, ¿desde qué momento?, ¿el hijo de crianza puede heredar de sus familiares por consanguinidad?, y, en sentido contrario, ¿los familiares de sangre del hijo de crianza, pueden heredar de este?

Finalmente, una aplicación amplia y flexible de la figura de familia de crianza puede llevar a que las personas se abstengan de proteger a menores que se encuentran en una situación de vulnerabilidad, por temor a que en un futuro, por haber 
ofrecido un trato afectivo y de apoyo a un menor, terminen siendo titulares de las obligaciones propias de un padre o una madre.

Ahora bien: resulta necesaria la expedición de una norma por parte del Congreso de la República para regular los aspectos más relevantes de la familia de crianza. Lo anterior, teniendo en cuenta la incertidumbre jurídica que rodea a esta figura y la necesidad de garantizar una debida protección a los integrantes de la estructura familiar. Asimismo la adopción de una norma resulta fundamental, teniendo en cuenta que el parentesco y las relaciones de familia son asuntos que debe decidir el legislador, más que el juez.

La promulgación de una ley por parte del órgano legislativo permitiría superar el déficit democrático que actualmente se presenta, pues las autoridades judiciales no son las llamadas a regular las relaciones de familia, habida cuenta de que al no ser elegidas popularmente, carecen de la representación democrática necesaria para abordar un asunto como el estudiado.

Sin el ánimo de señalar de forma detallada cual sería el contenido de una ley de esta naturaleza, dicha regulación debería abordar, al menos, los siguientes asuntos:

(1) Deben señalarse los requisitos o elementos necesarios para acreditar que existe una familia de crianza.

(2) La norma debe consagrar las consecuencias jurídicas que se derivan de la declaración de la existencia de una familia de crianza. En esta dirección, los efectos deben limitarse al campo sucesoral, de alimentos, visitas y de inhabilidades e incompatibilidades.

En este sentido, parece razonable adoptar una postura como la seguida por la jurisprudencia estadounidense y, de forma reciente, por la Corte Constitucional, en el sentido de que la familia de crianza no crea un vínculo de parentesco.

Esta posición encuentra justificación en el hecho de que de adoptarse una visión amplia de los efectos de la familia de crianza de manera que se entienda que las relaciones entre los miembros de dicha familia equivalen a las de una familia biológica o adoptiva, se estaría fomentando y permitiendo que las personas no se sometan a las estrictos procedimientos y normas vigentes en materia de adopción, los cuales fueron concebidos para garantizar la adecuada protección del menor que busca ser adoptado. Si una persona pretende que un menor con quien no se tiene vínculo de sangre o legal tenga los mismos derechos y obligaciones que un hijo biológico o adoptado, debe necesariamente acudir al procedimiento concebido por el legislador para el efecto.

De esta suerte, las consecuencias derivadas de la existencia de una familia de crianza deberían limitarse solamente a aquellos aspectos estrictamente necesarios para garantizar la protección del menor. Así, por ejemplo, debería reconocerse únicamente para efectos sucesorales y la regulación de alimentos y visitas.

También deben extenderse los efectos de la familia de crianza al campo de las inhabilidades e incompatibilidades, tal como ocurre con los parientes por consanguinidad o vínculo civil, pues ante la existencia de un vínculo tan estrecho e íntimo 
entre los integrantes de la familia de crianza, es necesario asegurar la toma de decisiones objetivas y evitar la existencia de conflictos de interés.

Por otra parte, debe incorporarse una restricción en el ámbito matrimonial, en términos similares a los señalados en el numeral 11 del artículo 140 del Código Civil. Es decir, debe calificarse de nulo el matrimonio celebrado entre los hijos y padres de crianza.

Asimismo debe establecerse si los efectos de la existencia de una familia de crianza corren a partir del momento en que ella es declarada, o desde el momento en que se inició el vínculo, tal como acontece en el caso de la unión marital de hecho. La postura que parecería más favorable sería esta última, pues garantiza una mayor protección a las partes.

(3) Para terminar, es necesario que la ley determine la forma en que debe declararse la existencia de una familia de crianza. Por ejemplo, a través de una declaración extrajuicio ante un notario, como ocurre actualmente con la unión marital de hecho, o por medio de un proceso judicial.

\section{Referencias}

BEAN, E., "Equitable adoption: a look at how to address pitfalls in Texas' complex process", Texas Bar Journal, vol. 81, n. o 9, 2018, 682-683.

DRAKE, R., "Status or contract? a comparative analysis of inheritance rights under equitable adoption and domestic partnership doctrines", Georgia Law Review, vol. 39 , n. ${ }^{\circ} 2,2005,675-731$.

Esborraz, D. F. "El concepto constitucional de familia en América Latina. Tendencias y proyecciones", Revista de Derecho Privado, n. . 29, 2015, 15-55.

Farnsworth, E., Contracts, $4^{\text {th }}$ edition, Aspen Publishers, New York, 2004.

Ferrer, F., "Introducción al derecho de familia", en Derecho de familia, tomo I, Rubinzal-Culzoni editores, 1984.

Fougeron, K., "Equitable Considerations for Families with Same-Sex Parents: Russell v. Bridgens, 264 Neb. 217, 647 N.W.2d 56 (2002), and the Use of the Doctrine of In Loco Parentis by Nebraska Courts", Nebraska Law Review, vol. 83, n. ${ }^{\circ} 3,2005,915-931$.

Herrera Guerrero, B.; Weisser Soto, B.; Salazar Salazar, D., "Imágenes y conceptos de familia expresados en las representaciones sociales de mujeres de sectores urbano-populares de la ciudad de Temuco", Chile, Limite, Universidad de Tarapacá, vol. 1, n. ${ }^{\circ} 11,2004,1-34$. 
Higdon, M., "When informal adoption meets intestate succession: the cultural myopia of the equitable adoption doctrine", Wake Forest Law Review, vol. 43, n. ${ }^{1}$, 2008, 223-281.

Johnson, I., "A suggested solution to the problem of intestate succession in nontraditional family arrangements: taking the 'adoption' (and the inequity) out of the doctrine of 'equitable adoption", Saint Louis University Law Journal, vol. 54, n. ${ }^{\circ} 1,2009,271-333$.

Levine, B., "Divorce and the modern family: providing in loco parentis stepparents standing to sue for custody of their stepchildren in a dissolution proceeding", Hofstra Law Review, vol. 25, n. ${ }^{\circ}$ 1, 1996, 315-352.

Lorca Martín de Villodres, M., "La experiencia jurídica actual desde la clásica doctrina filosófica de la naturaleza de las cosas", Persona y derecho, Universidad de Navarrra, vol. 68, n. ${ }^{\circ} 1,2013,39-75$.

Messio, P., "La función social del derecho. El derecho vivo", Revista de la Asociación de Magistrados y funcionarios de la Justicia de la Nación [en línea], IJ Editores, vol. 39/40 - n. ${ }^{o}$ enero/junio, 2006. Disponible en http://ijeditores. com/articulos.php?idarticulo $=48986 \&$ print $=2$ [consultado el 20 de noviembre de 2018].

Metta, M. y Markus, S., "Family law: virtual adoption: contractual estoppel of parental rights and responsibilities", The Florida Bar Journal, vol. 71, n. 5 1997, 90 .

Oliva Gómez, E. y Villa Guardiola, V. "Hacia un concepto interdisciplinario de la familia en la globalización”, Justicia Juris, vol. 10, n. 1, 2014, 11-20.

Pérez Contreras, M., Derecho de familia y sucesiones, México D. F., Nostra Ediciones, 2010.

Petri, C., "What's in a Name? Not Much for Equitable Adoption in Missouri", Missouri Law Review, vol. 63, n. ${ }^{\circ} 1,1998,195-224$.

ReEves, W., "Inheritance by equitable adoption: an overview of theory and proof", Journal of the Missouri Bar, vol. 57, n. ${ }^{\circ}$ 3, 2001, 130-135.

Robinson, J., “Untangling the 'loose threads': equitable adoption, equitable legitimation, and inheritance in extralegal family arrangements", Emory Law Journal, vol. 48, n. ${ }^{\circ}$ 3, 1999, 943-990. 
Strachman, D., "Equitable adoption doctrine", Rhode Island Bar Journal, vol. 64, 2016.

Survey. "Deference Defiantly Denied: The Fourth Circuit Rejects NLRB Position on

$\S 8(f)$ Pre-hire Agreements in Industrial TurnAround Corp. v. NLRB", en North Carolina Law Review, vol. 76, n. ${ }^{\circ}$ 6, 1998, 2480.

WARNER, L., "Local government law symposium: student work: bending the bow of equity: three ways Florida can improve its equitable adoption policy", Stetson Law Review, vol. 38, n. ${ }^{\circ}$ 3, 2009, 577-618.

\section{Jurisprudencia}

Alaska Supreme Court, Calista Corp. v. Mann, 564 P.2d 53, 1977.

Corte Constitucional, sentencia T-217 de 1994.

Corte Constitucional, sentencia T-495 de 1997.

Supreme Court of North Carolina, Lankford v. Wright, 347 N.C. 115, 1997.

Supreme Court of Pennsylvania, Tb v. Lrm, 786 A.2d 913, 2001.

California Supreme Court. In Re Estate of Ford, 82 P.3d 747, 2004.

Missouri Court of Appeals, Coon v. American Compressed Steel, 133 S.W.3d 75, 2004.

Corte Constitucional, sentencia T-292 de 2004.

Corte Constitucional, sentencia T-497 de 2005.

Court of Appeals of New Mexico. Poncho v. Bowdoin, 126 P.3d 1221, 2005.

Corte Constitucional, sentencia C-903 2008.

Corte Constitucional, sentencia T-887 de 2009.

Court of Appeals of Ohio, State v. Abubakar, 2011-Ohio-6299, 2011.

Supreme Court of Nebraska, Latham v. Schwerdtfeger, 802 N.W.2d 66, 2011. 
Corte Constitucional, sentencia T-606 de 2013.

Appellate Court of Illinois, In re Marriage of Mancine, 2014 IL App (1st) 111138, 2014.

Supreme Court of Arkansas, Foust v. Montez-Torres, 2015 Ark. 66, 2015.

Court of Appeals of Mississippi, Roger Lynn Neely v. Kaleb Matthew Welch, 2014CA-01022-COA, Miss. Ct. App. 2015.

Corte Constitucional, sentencia T-111 de 2015.

Corte Constitucional, sentencia T-233 de 2015.

Corte Suprema de Justicia. Sala de Casación Civil y Agraria. Sentencia del 23 de octubre de 2015, rad. n. ${ }^{\circ}$ 2500122130002015-00361-02.

Supreme Court of Illinois, James R. D. v. Maria Z. (In re Scarlett Z.-D.), 28 N.E.3d 776, 2015.

Consejo de Estado, Sección Tercera, sentencia del 14 de septiembre de 2016, rad. 81001-23-31-000-2009-00035-01.

Nebraska Supreme Court, Windham v. Griffin, 295 Neb. 279, 2016.

Corte Constitucional, sentencia T-525 de 2016.

Corte Constitucional, sentencia T-705 de 2016.

Nebraska Supreme Court, Whilde v. Whilde, 298 Neb. 473, 2017.

Court of Appeals of Arkansas, McCrillis v. Hicks, 2017 Ark. App. 221, 2017.

Corte Constitucional, sentencia T-177 de 2017.

Consejo de Estado, Sección Segunda, sentencia del 27 de noviembre de 2017, rad. 25000-23-42-000-2017-02526-01(AC).

Consejo de Estado, Sección Tercera, sentencia del 5 de diciembre de 2017, rad. 47001-23-31-000-2009-00002-01(41941). 
Corte Suprema de Justicia, Sala de Casación Civil, sentencia del 9 de mayo de 2018, rad. 25000-22-13-000-2018-00071-01.

Nebraska Supreme Court, Jennifer T. v. Lindsay P., 298 Neb. 800, 2018.

Corte Constitucional, sentencia T-281 de 2018.

Corte Constitucional, sentencia C-085 de 2019. 